\title{
Synthesis of a Novel Calix[4]resorcinarene-Chitosan Hybrid
}

\section{PRIO SANTOSO ${ }^{1 *}$, CHAIRIL ANWAR ${ }^{2}$, JUMINA ${ }^{2}$, DWI SISWANTA ${ }^{2}$, SUHARSO $^{3}$ and KEISUKE OHTO ${ }^{4}$}

\author{
'Department of Chemistry, Faculty of Sciences, Institut Teknologi Sumatera, \\ Lampung 35365, Indonesia. \\ ${ }^{2}$ Department of Chemistry, Faculty of Mathematics and Natural Sciences, \\ University of Gadjah Mada, Yogyakarta 55281, Indonesia. \\ ${ }^{3}$ Department of Chemistry, Faculty of Mathematics and Natural Sciences, \\ University of Lampung, Lampung 35145, Indonesia. \\ ${ }^{4}$ Saga University, 1-Honjo, Saga 840-8502, Japan. \\ *Corresponding author E-mail: santosoprio99@gmail.com
}

http://dx.doi.org/10.13005/ojc/340103

(Received: November 26, 2017; Accepted: January 01, 2018)

\begin{abstract}
Synthesis of a novel calix[4]resorcinarene-chitosan hybrid using vanillin as raw material has been conducted. The synthesis was carried out in four steps i.e. (1) allylation of vanillin, (2) $\mathrm{HCl}$-catalyzed condensation allyl vanillin with resorcinol, (3) chloromethylation of C-4-allyloxy-3-methoxyphenylcalix[4] resorcinarene with paraformaldehyde and $\mathrm{HCl}$ in the presence of $\mathrm{ZnCl}_{2}$ to yield tetrakis-chloromethyl-C-4-allyloxy-3 methoxyphenylcalix[4]resorcinarene, and (4) reaction of tetrakis-chloromethyl-C-4-allyloxy-3-methoxyphenylcalix[4] resorcinarene with chitosan to yield calixarene-chitosan hybrid. Structure elucidation of products were performed using FT-IR, ${ }^{1} \mathrm{H}-\mathrm{NMR},{ }^{13} \mathrm{C}-\mathrm{NMR}, \mathrm{GC}-\mathrm{MS}, \mathrm{XRD}$, and SEM. The product of calixarene-chitosan hybrid was obtained as dark red solid with m.p. $>300{ }^{\circ} \mathrm{C}$ in $78 \%$ yield.
\end{abstract}

Keywords: Calixarene modification synthesis, Chitosan hybrid, Novel calix[4]resorsinarenes, Vanillin.

\section{INTRODUCTION}

Calixarene has attracted the attention of scientists since it was first introduced in $1978^{1}$ because it can be utilized in various fields. Calixarene has been studied its use for various purposes, including: sunscreen, ${ }^{2}$ extraction, ${ }^{3}$ inhibitor of calcium carbonate ${ }^{4,5}$ and calcium sulphate ${ }^{6}$ scale formation, a stationary phase of HPLC, ${ }^{7,8}$ drug delivery, ${ }^{9}$ antioxidant and anti-toxoplasma, ${ }^{10}$ dye fibers, ${ }^{11}$ biosensors, ${ }^{12}$ and adsorbent ${ }^{13,14}$. Calixarene is compound group of

This is an $\mathbf{C}$ Open Access article licensed under a Creative Commons Attribution-NonCommercial-ShareAlike 4.0 International License (https://creativecommons.org/licenses/by-nc-sa/4.0/ ), which permits unrestricted NonCommercial use, distribution and reproduction in any medium, provided the original work is properly cited. 
synthetic oligomer containing aromatic ring in a cyclic sequence linked by a methylene group ${ }^{1}$. One derivate of this compound that has been studied is calix[4]resorcinarene ${ }^{15-17}$. Calix[4]resorcinarene (Fig. 1) consists of 4 units of resorcinol in the form of cyclic linked by a methylene bridge. It can be synthesized by reaction of resorcinol with an aldehyde under acidic conditions.<smiles>[R2]c1c(O)c2cc(c1O)C([R])c1cc(c(O)c([R2])c1O)C([R])c1cc(c(O)c([R2])c1O)C([R])c1cc(c(O)c([R2])c1O)C2[R]</smiles>

Fig. 1. Structure of calix[4]resorcinarene

A number of studies have shown that research developments of calixarene more focused on modifying the calixarene structure by adding a variety of new functional groups. Timmerman and his colleagues have been succes to synthesize and modify a wide variety of calix[4]resorcinarene by varying groups at $R_{1}$ and $R_{2}{ }^{18}$. Groups at $R_{1}$ can be varied by using aldehyde different as the reagent forming of calix[4]resorcinarene. While groups at $\mathrm{R}_{2}$ can be varied via electrophilic substitution reaction of calix[4]resorcinarene. Because a position between $\mathrm{OH}$ in the aromatic ring of resorcinol has high electron density so it is very reactive to the presence of an electrophilic. ${ }^{19}$

In this research, the new calixarene produced was derived from reaction between resorcinol and vanillin as a source of aldehyde functional group. In addition, modification of calixarene structure was performed by reacting chitosan with calix[4]resorcinarene at $R_{2}$ position formed a calix[4]resorcinarene-chitosan hybrid. Anggraini has been successfully produced calix[4]resorcinarene-chitosan hybrid from chitosan and C-4-methoxycarbonilmethoxy-3-methoxyphenylcalix [4]resorcinarene through amide bond formation at $R_{1}$ group $^{20}$. The product has sufficiently low yield, which is $28 \%$. In this research, the hybrid was synthesized through bond formation of secondary amine between the amine group of chitosan with chloromethyl group of tetrakis-chloro methyl-C-4alyloxy-3 methoxyphenylcalix[4]resorcinarene at $R_{2}$ group. $\mathrm{Cl}$ atom on the alkyl halide is better leaving group than $-\mathrm{OCH}_{3}$ at the carbonyl group, so the hybrid formation reactions in this research would be easier to happen and has a high yield.

\section{MATERIALS AND METHODS}

\section{Materials and equipments}

Chemicals used in this research were vanillin, resorcinol, allyl bromide, chitosan, paraformaldehyde, zinc chloride $\left(\mathrm{ZnCl}_{2}\right), \mathrm{Pb}$, ethanol, methanol, acetone, N,N-dimethyl formamide (DMF), dichloromethane, hydrochloric acid $(\mathrm{HCl} 37 \%)$, sodium sulfate $\left(\mathrm{Na}_{2} \mathrm{SO}_{4}\right)$ anhydrate, ethyl acetate (EtOAc), and distilled water. All chemicals except distilled water were purchased from E. Merck KG. Distilled water was obtained from Laboratory of Fundamental Chemistry, University of Gadjah Mada.

Equipment used in this research were laboratory glassware, hot plate with magnetic stirrer, Büchner funnel, Buchi R-124 Rotary Vap System (Marshall Scientific), analytical mass balance (Mettler AT 200, Mettler Instrument Corp. Switzerland), infra-red spectrophotometer (IR, Shimadzu-Prestige 21, Japan), proton nuclear magnetic resonance spectrometer ( ${ }^{1} \mathrm{H}-\mathrm{NMR}$, JEOL JNM-MY60 and JEOL MY-500 MHz, USA), carbon nuclear magnetic resonance spectrometer $\left({ }^{13} \mathrm{C}-\mathrm{NMR}\right.$, JEOL MY-500 $\mathrm{MHz}, \mathrm{USA}$ ), gas chromatography-mass spectrometer (GC-MS, Shimadzu QP-5000, Japan), X ray diffraction (XRD Shimadzu 6000, Japan) and scanning electron microscope (SEM, Jeol JSM T300, USA).

\section{Procedures}

As much as $15 \mathrm{~mL}$ of ethanol was added into $100 \mathrm{~mL}$ of three-necked-flask. Then, $0.38 \mathrm{~g}$ (16.40 mmol) of sodium metal was added and stirred until it was dissolved completely to produce sodium ethoxide. After that, $1.25 \mathrm{~g}(4.10 \mathrm{mmol})$ of vanillin was added and refluxed for 1 hour. Then, as much as $1.99 \mathrm{~g}(16.40 \mathrm{mmol})$ of allyl bromide was added portion by portion into the mixture of sodium ethoxide and vanillin. The mixture was then refluxed for 24 hours. The solution was evaporated, washed with $30 \mathrm{~mL}$ of $\mathrm{NaOH} 0.1 \mathrm{M}$ and extracted with 
$20 \mathrm{~mL}$ of dichloromethane three times. The combined organic layer was washed with distilled water and dried with $\mathrm{Na}_{2} \mathrm{SO}_{4}$ anhydrate, filtered and evaporated. The product 1 was obtained as brown yellowish liquid in $72 \%$ yield; FT-IR $(\mathrm{KBr}) \mathrm{v}$ $\left(\mathrm{cm}^{-1}\right): 1682$ ( $\mathrm{C}=\mathrm{O}$ aldehyde), 1589 and 1512 (C=C aromatic), 1134 (C-O-C); ${ }^{1} \mathrm{H}-\mathrm{NMR}(500 \mathrm{MHz}$, $\left.\mathrm{CDCl}_{3}\right) \delta(\mathrm{ppm}): 9.83(1 \mathrm{H}, \mathrm{s},-\mathrm{HC}=\mathrm{O}), 7.40(1 \mathrm{H}, \mathrm{d}, \mathrm{ArH})$, $7.03(1 \mathrm{H}, \mathrm{s}, \mathrm{ArH}), 6.97(1 \mathrm{H}, \mathrm{d}, \mathrm{ArH}), 6.00(1 \mathrm{H}, \mathrm{m},-\mathrm{CH}=)$, 5.33 and $5.31\left(2 \mathrm{H}, \mathrm{d}\right.$ of $\mathrm{d}, \mathrm{H}_{2} \mathrm{C}=$ allyl), 4.69 (2H,d,- $\mathrm{CH}_{2}$ - allyl), $3.92\left(3 \mathrm{H}, \mathrm{s},-\mathrm{CH}_{3}\right) ;{ }^{13} \mathrm{C}-\mathrm{NMR}(126$ $\left.\mathrm{MHz}, \mathrm{CDCl}_{3}\right) \delta(\mathrm{ppm}): 191$ (Ar- $\left.\underline{\mathrm{C}}=\mathrm{O}\right), 154,150,130$, 127, 112, 109 (Ar), 132 (- $\underline{\mathrm{C}} \mathrm{H}=$ allyl), 119 $\left(\mathrm{H}_{2} \mathrm{C}=\right.$ allyl), $70\left(-\mathrm{CH}_{2}-\right.$ allyl), $56\left(-\underline{\mathrm{CH}}_{3}\right)$; GC-MS: rt $=30 \mathrm{~min}$, purity $87 \%, \mathrm{~m} / \mathrm{z} 192 \mathrm{~g} / \mathrm{mol}$.

\section{Synthesis of C-4-allyloxy-3methoxyphenylcalix [4]resorcinarene (2)}

In $100 \mathrm{~mL}$ three-necked flask equipped with water condenser, $0.87 \mathrm{~g}(4.54 \mathrm{mmol})$ of 4-allyloxy-3-methoxy benzaldehyde and $0.50 \mathrm{~g}$ $(4.54 \mathrm{mmol})$ of resorcinol were dissolved in $20 \mathrm{~mL}$ of ethanol. Then, concentrated hydrochloric acid $(0.5 \mathrm{~mL})$ was added into the solution. The mixture was refluxed for $24 \mathrm{~h}$ and evaporated. The solid was washed using the mixture of distilled water and ethanol (1:1) and dried. The product 2 was obtained as a white solid with m.p. $235-236{ }^{\circ} \mathrm{C}$ in $64 \%$ yield; FT-IR $(\mathrm{KBr}) \vee\left(\mathrm{cm}^{-1}\right): 3426(\mathrm{OH})$, 1612 and 1512 ( $\mathrm{C}=\mathrm{C}$ aromatic), 1134 (C-O-C); ${ }^{1} \mathrm{H}-\mathrm{NMR}\left(500 \mathrm{MHz}, \mathrm{CD}_{3} \mathrm{OD}\right): 6.53$ (1H,s,ArH), 6.47 $(1 \mathrm{H}, \mathrm{d}, \mathrm{ArH}), 6.29(1 \mathrm{H}, \mathrm{d}, \mathrm{ArH}), 6.25(1 \mathrm{H}, \mathrm{s}, \mathrm{ArH})$, $6.20(1 \mathrm{H}, \mathrm{s}, \mathrm{ArH}), 5.61-5.77(1 \mathrm{H}, \mathrm{m},-\mathrm{CH}=)$, 5.21$5.39\left(2 \mathrm{H}, \mathrm{d}\right.$ of $\left.\mathrm{d}, \mathrm{H}_{2} \mathrm{C}=\right), 4.61(1 \mathrm{H}, \mathrm{s},-\mathrm{CH}$ methylene group), $4.54\left(2 \mathrm{H}, \mathrm{d},-\mathrm{CH}_{2}-\right), 3.57\left(3 \mathrm{H}, \mathrm{s},-\mathrm{CH}_{3}\right) ;{ }^{13} \mathrm{C}-$ NMR (126 MHz, CD $\left.{ }_{3} \mathrm{OD}\right) \delta(\mathrm{ppm}): 154,150,147$, 140, 132, 124, 122, 115, 114, $104(\mathrm{Ar}), 136(-\mathrm{CH}=$ allyl), $117\left(\mathrm{H}_{2} \mathrm{C}=\right.$ allyl), $71\left(-\mathrm{CH}_{2}-\right.$ allyl), $56\left(-\mathrm{CH}_{3}\right)$, 43 (- $\underline{\mathrm{CH}}$ methylene group).

\section{Synthesis of tetrakis-chloromethyl-C-4-allyoxy- 3-methoxyphenylcalix [4]resorcinarene (3)}

Into $100 \mathrm{~mL}$ three-necked flask, C-4-allyloxy-3methoxyphenylcalix[4]resorcinarene $(1.44 \mathrm{~g}, 1.27 \mathrm{mmol}$ ) was dissolved in $35 \mathrm{~mL}$ of DMF. Then, paraformaldehyde $(0.23 \mathrm{~g}, 7.67 \mathrm{mmol}), \mathrm{ZnCl}_{2}$ $(1.50 \mathrm{~g}, 11 \mathrm{mmol})$ and concentrated hydrochloric acid $(8 \mathrm{~mL})$ were added to the solution, respectively. The mixture was heated at $120^{\circ} \mathrm{C}$ for 22 hours. The trituration of the cool reaction mixture using distilled water was then carried out to give the precipitate.
The formed solid was then filtered, washed with distilled water and dried in the oven. The dried solid was recrystallized with methanol-water. The product 3 was obtained as a light brown solid in $71 \%$ yield with m.p. $>250^{\circ} \mathrm{C}$ (decomposed). FT-IR (KBr) $v\left(\mathrm{~cm}^{-1}\right)$ : $3426(\mathrm{OH}), 1605$ and $1504(\mathrm{C}=\mathrm{C}$ aromatic), $1450\left(-\mathrm{CH}_{2}-\right), 1080$ (C-O-C); ${ }^{1} \mathrm{H}-\mathrm{NMR}(500 \mathrm{MHz}$, $\left.\mathrm{CD}_{3} \mathrm{OD}\right): 8.51(2 \mathrm{H}, \mathrm{s}, \mathrm{OH}), 6.17-6.56(4 \mathrm{H}, \mathrm{s}, \mathrm{ArH})$, 5.55-5.85 $(1 \mathrm{H}, \mathrm{m},-\mathrm{CH}=), 5.15-5.55\left(2 \mathrm{H}, \mathrm{d}\right.$ of $\left.\mathrm{d}, \mathrm{H}_{2} \mathrm{C}=\right)$, $4.85\left(1 \mathrm{H}, \mathrm{s},-\mathrm{CH}\right.$ methylene bridge), $4.45\left(2 \mathrm{H}, \mathrm{d},-\mathrm{CH}_{2}-\right)$, $3.42\left(3 \mathrm{H}, \mathrm{s},-\mathrm{CH}_{3}\right), 3.10\left(2 \mathrm{H}, \mathrm{s},-\mathrm{CH}_{2}-\mathrm{Cl}\right) ;{ }^{13} \mathrm{C}-\mathrm{NMR}$ $\left(126 \mathrm{MHz}, \mathrm{CD}_{3} \mathrm{OD}\right) \delta(\mathrm{ppm}): 153,148,145,139,135$, 117, 115, 112, 113, 102 (Ar), 137 (-ㅁH= allyl), $114\left(\mathrm{H}_{2} \underline{\mathrm{C}}=\right.$ allyl), $69\left(-\underline{\mathrm{CH}}_{2}-\right.$ allyl), $55\left(-\underline{\mathrm{CH}}_{3}\right), 40$ (- $\underline{\mathrm{CH}}$ methylene group), $34\left(-\underline{\mathrm{C}} \mathrm{H}_{2}-\mathrm{Cl}\right)$.

Synthesis calix[4]resorcinarene-chitosan hybrid (4) Mixture of chitosan $(0.43 \mathrm{~g}, 2.40 \mathrm{mmol})$, tetrakis-chloromethyl-C-4-allyoxy-3-methoxyphenyl calix[4] resorcinarene $(0.32 \mathrm{~g}, 0.24 \mathrm{mmol})$ and DMF $(30 \mathrm{~mL})$ in the $100 \mathrm{~mL}$ three-necked-flask was refluxed for 24 hours. Product was cooled, filtered and washed with distilled water until the solid was formed. The formed solid was filtered and dried. The product 4 was obtained as a dark red solid with m.p. $>250{ }^{\circ} \mathrm{C}$ (decomposed) in $78 \%$ yield. FT-IR $(\mathrm{KBr}) \vee\left(\mathrm{cm}^{-1}\right)$ : $3426(\mathrm{OH}), 1605$ and 1512 $(\mathrm{C}=\mathrm{C}$ aromatic), 1142 (C-O-C).

\section{RESULTS AND DISCUSSION}

Synthesis of calix[4]resorcinarenechitosan hybrid compound was carried out in four steps i.e. allylation of vanillin, condensation allyl vanillin with resorcinol to yield 4-allyloxy-3methoxyphenylcalix[4]resorsinarene, chloromethylation of C-4-allyloxy-3-methoxyphenylcalix[4], and reaction of tetrakis-chloro methyl-C-4-allyloxy-3methoxyphenylcalix[4]resorcinarene with chitosan to yield calix[4]resorcinarene-chitosan hybrid. Synthesis scheme of calix[4]resorcinarene-chitosan hybrid was presented in Figure. 2.

Allylation of vanillin produce 4-allyloxy-3methoxybenzaldehyde compound was performed by inserting $\mathrm{Na}$ into ethanol in a $100 \mathrm{~mL}$ three neck flask. The mixture was stirred until all the Na reacts generate sodium ethanolic. The sodium ethanolic is a strong base so it will take $\mathrm{H}^{+}$from the group 
of phenol contained in vanillin (4-hydroxy-3-methoxy benzaldehyde) produced strong nucleophile. The nucleophile will attack the $\mathrm{C}$ atoms which charged positive partial binding $\mathrm{Br}$ in allyl bromide. This reaction is predicted through $\mathrm{S}_{\mathrm{N}} 2$ mechanism. This is due to a nucleophile formed in this reaction is a strong nucleophile and alkyl halides involved in the reaction are primary alkyl halide which very open to attack by a nucleophile. Compound of 4-allyloxy-3-methoxybenzaldehyde was obtained as brown yellowish liquid in $72 \%$ yield. Then it was characterized with IR spectrometer, ${ }^{1} \mathrm{H}-\mathrm{NMR}$, ${ }^{13} \mathrm{C}-\mathrm{NMR}$ and GC-MS. FT-IR spectra showed absorption of $\mathrm{C}=\mathrm{O}$ aldehyde, $\mathrm{C}=\mathrm{C}$ aromatic, and $\mathrm{C}-\mathrm{O}-\mathrm{C}$ groups. The most important information of the FT-IR spectra is the loss absorption of $\mathrm{OH}$ group at $3200-3400 \mathrm{~cm}^{-1}$. This indicates that $\mathrm{OH}$ group at vanillin has been allylated.

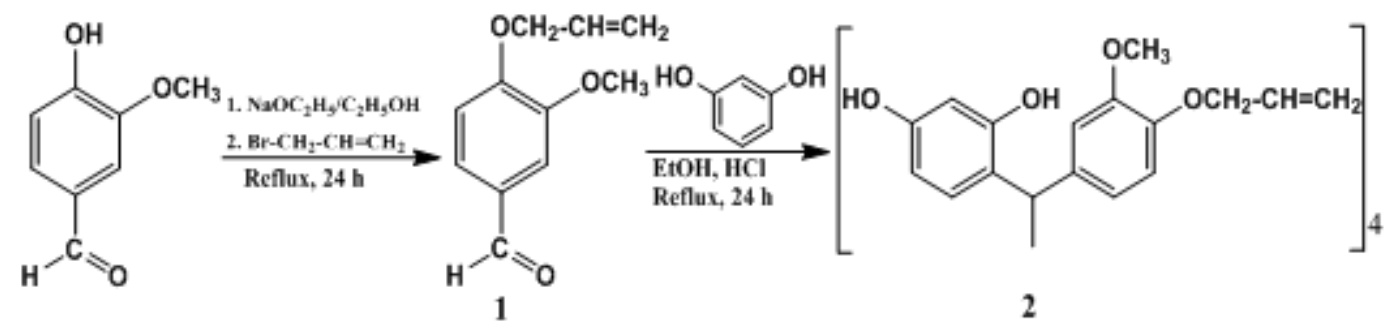

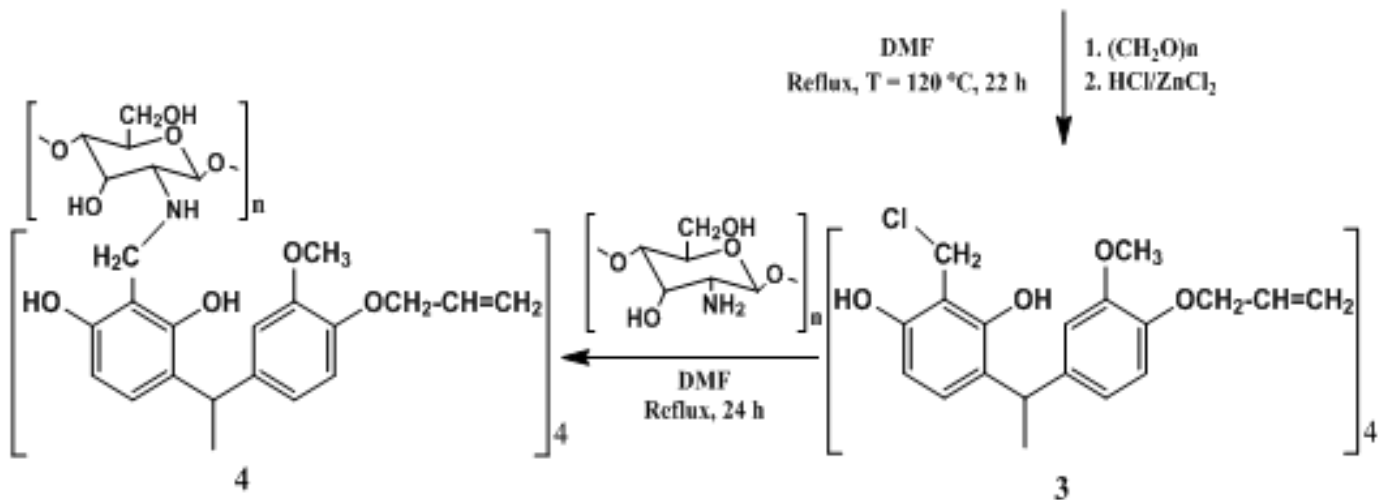

Fig. 2. Synthesis scheme of calix[4]resorcinarene-chitosan hybrid from vanillin

Based on ${ }^{1} \mathrm{H}-\mathrm{NMR}$ spectra, there are nine hydrogens are in a different environments. Singlet signal at $9.83 \mathrm{ppm}$ showed one proton aldehyde group. Three signals at $7.40 \mathrm{ppm}$ (duplet), $7.03 \mathrm{ppm}$ (singlet) and $6.97 \mathrm{ppm}$ (duplet) showed protons aromatic group. Multiplet signal at $6.00 \mathrm{ppm}$ shift shows 1 proton $-\mathrm{CH}=$ the allyl group. Two protons of $\mathrm{H}_{2} \mathrm{C}=$ were shown at $5.33 \mathrm{ppm}$ (duplet of duplet) and $5.31 \mathrm{ppm}$ (duplet of duplet). Two protons of $-\mathrm{CH}_{2}$ - the allyl group were shown by duplet signal at $4.69 \mathrm{ppm}$ and three protons of $-\mathrm{CH}_{3}$ were shown by shift at $3.92 \mathrm{ppm}$. Characterization of vanillin allylation product was resumed with ${ }^{13} \mathrm{C}$-NMR spectrometer. Spectra of ${ }^{13} \mathrm{C}$-NMR showed that the compound of 1 contained $11 \mathrm{C}$ atoms in different environments. $\mathrm{C}$ atom of carbonyl was shown by signal at $191 \mathrm{ppm}$. Six C atoms of aromatic group were shown by signal at 154, 150, 130, 127, 112 and $109 \mathrm{ppm}$. Three $\mathrm{C}$ atoms of allyl $\left(-\underline{\mathrm{CH}}=, \mathrm{H}_{2} \mathrm{C}=,-\mathrm{CH}_{2}-\right)$ were shown by signal at 132,119 and $70 \mathrm{ppm}$. One $\mathrm{C}$ atom of methoxy was shown by at $56 \mathrm{ppm}$. The last characterization product of vanillin allylation was performed using GC-MS. The use of GC-MS aimed to determine purity and confirmed the relative molecular mass of product. Based on data from GC-MS, product has $87 \%$ purity, $192 \mathrm{~g} / \mathrm{mol}$ molecular weight and $30 \mathrm{~min}$. retention time.

Synthesis of C-4-allyloxy-3methoxypheny Icalix[4]resorcinarene compound was conducted by reacting resorcinol and 4-allyloxy-3-methoxy benzaldehyde results of previous phase synthesis using $\mathrm{HCl}$ for catalyst in ethanol. The mixture was refluxed at $78{ }^{\circ} \mathrm{C}$ for 24 hours. Formation of C-4-allyloxy-3-methoxyphenylcalix[4]resorcinarene was preceded by protonation of the carbonyl group 
4-allyloxy-3-methoxy benzaldehyde to form carbonyl group which is positively charged. The existence of positive charge causes double bond of carbonyl group conjugated to the oxygen atom. It causes carbon atom of the carbonyl group to be positively charged. Then carbon atom which positively charged will be attacked by a double bond of carbon atom number 4 on the benzene ring of resorcinol. A second carbocation formed again after releasing a water molecule. The next step was cyclization through attack of second carbocation by electron double bond of carbon atom number 4 on the benzene ring of resorcinol. This happened repeatedly until formed calix[4]resorcinarene. Compound of C-4-allyloxy 3-methoxy phenylcalix [4]resorcinarene was obtained as a as a white solid with m.p. $235-236{ }^{\circ} \mathrm{C}$ in $64 \%$ yield. Furthermore, to ensure that the compound of 2 has formed, structure elucidation was conducted by FT-IR, ${ }^{1} \mathrm{H}-\mathrm{NMR}$ and ${ }^{13} \mathrm{C}-\mathrm{NMR}$ spectrometry.

Based on the data from FT-IR spectra, it was obtained information that the compound C-4-allyloxy-3-methoxyphenylcalix[4]resorcinarene which was synthesized containing $\mathrm{OH}$ groups. This was shown by absorption band at $3426 \mathrm{~cm}^{-1}$. Absorption bands at 1512 and $1612 \mathrm{~cm}^{-1}$ indicate the presence of $\mathrm{C}=\mathrm{C}$ aromatic groups. The presence of ether groups (C-O-C) was shown by an absorption band at $1134 \mathrm{~cm}^{-1}$. Absorption band at $1682 \mathrm{~cm}^{-1}$ shows the aldehyde carbonyl group $(\mathrm{C}=\mathrm{O})$ in 4-allyloxy-3-methoxybenzaldehyde as the reactants have been lost. This indicates that the formation of bonds between carbon atom number 4 and 6 in resorcinol with carbon atom atom of carbonyl at the 4-allyloxy-3-methoxybenzaldehyde formed methylene bridge.

Further characterization by ${ }^{1} \mathrm{H}-\mathrm{NMR}$ spectrometer was obtained information that there are at least 10 types of protons that can be identified in different environments in the C-4-allyloxy-3methoxyphenylcalix[4]resorcinarene synthesized. Singlet proton at $3.57 \mathrm{ppm}$ shows proton at methoxy group $\left(-\mathrm{OCH}_{3}\right)$. Singlet proton at $4.54 \mathrm{ppm}$ shows proton of $-\mathrm{CH}_{2}$ - allyl group. Singlet protons at $4.61 \mathrm{ppm}$ shows proton of methylene bridge. Protons at 5.21-5.39 ppm with the appearance duplet of duplet indicated proton of $=\mathrm{CH}_{2}$ allyl group. Protons at 5.61-5.77 ppm with the appearance multiplet show proton of $-\mathrm{CH}=$ allyl group. Protons at 6.20 and $6.53 \mathrm{ppm}$ with the appearance show proton of resorcinol aromatic ring. Protons at $6.25,6.29$, and $6.47 \mathrm{ppm}$ with the appearance singlet, duplet, and duplet respectively show protons of allyl vanillin aromatic ring.

Further characterization using ${ }^{13} \mathrm{C}-\mathrm{NMR}$ spectrometer shows that all of the carbons appear in the appropriate area. The carbon of methylene bridge appears at $43 \mathrm{ppm}$, the carbon of methoxy seems at $56 \mathrm{ppm}$, the carbons of allyl are indicated at 71,117 , and $136 \mathrm{ppm}$. The carbons for aromatic benzene ring which come from vanillin can be identified at 114, 115, 122, 140, 147, and $150 \mathrm{ppm}$. While, the carbons of aromatic benzene ring from resorcinol can be seen at 104, 124, 132, and $154 \mathrm{ppm}$. The data of carbon shift of C-4-allyloxy-3methoxyphenilcalix[4]resorcinarene compound have a shift similar to the shift shown in chem draw software. Based on data from FT-IR, ${ }^{1} \mathrm{H}-\mathrm{NMR}$ and ${ }^{13} \mathrm{C}$-NMR spectrometer can be concluded that the C-4-allyloxy-3-methoxyphenilcalix[4]resorcinarene has been formed.

Tetrakis-chloromethyl-C-4-allyloxy-3methoxyphenylcalix[4]resorcinarene was produced through two reaction stages. The first stage is an electrophilic substitution reaction, while the second stage is a nucleophilic substitution reaction with zinc chloride as a catalyst in both reactions. Tetrakischloromethyl-C-4-allyloxy-3-methoxyphenylcalix[4] resorcinarene was synthesized by reacting C-4-allyloxy-3-methoxyphenylcalix [4]resorcinarene with paraformaldehyde, zinc chloride and concentrated hydrochloric acid in N,N-dimethylformamide. The compound of Tetrakis-chloromethyl-C-4-allyloxy-3methoxyphenylcalix[4] resorcinarene was obtained as a light brown solid in $71 \%$ yield with m.p. $>250^{\circ} \mathrm{C}$ (decomposed). Increasing of melting point of compound 3 compared to compound 2 was predicted by increasing of polarity due to the inclusion chloromethyl and increasing of relative molecular mass from $1137 \mathrm{~g} \mathrm{~mol}^{-1}$ to $1331 \mathrm{~g} \mathrm{~mol}^{-1}$. Furthermore compound 3 was characterized by IR, ${ }^{1} \mathrm{H}-\mathrm{NMR}$, and ${ }^{13} \mathrm{C}-\mathrm{NMR}$ spectrometer.

Based on identify of IR spectra performed, it was obtained information the $\mathrm{OH}$ group absorption that appeared in the $3426 \mathrm{~cm}^{-1}$. The absorbance of $\mathrm{C}=\mathrm{C}$ aromatic group existed at 1504 and $1605 \mathrm{~cm}^{-1}$. 
The absorbance of C-O-C group was displayed at $1142 \mathrm{~cm}^{-1}$. The absorbance of $-\mathrm{CH}_{2}-$ at $1450 \mathrm{~cm}^{-1}$ indicated that chloromethylation reaction of C-4-allyloxy-3-methoxyphenylcalix[4] resorcinarena have done successfully. Further characterization of chloromethylation product was done by ${ }^{1} \mathrm{H}-\mathrm{NMR}$ and ${ }^{13} \mathrm{C}-\mathrm{NMR}$ spectrometer.

From the result of ${ }^{1} \mathrm{H}-\mathrm{NMR}$, least 8 protons were in a different environments. Success of chloromethylation reaction was shown by presence of chemical shift at $3.10 \mathrm{ppm}$ in the form singlet proton which indicates proton of chloromethyl group. This is similar to the result proton chloromethyl of tetrakis-chloromethyl-C-4methoxyphenylcalix [4]resorcinarene which was synthesized by Utomo, et al., (2011) ${ }^{20}$. The next characterization using ${ }^{13} \mathrm{C}-N M R$ showed that all of the carbons appear in the appropriate area with the chloromethyl carbon at $34 \mathrm{ppm}^{19}$. The methylene bridge carbon identified at $40 \mathrm{ppm}$, the methoxy carbon existed at $55 \mathrm{ppm}$, and the carbons of allyl group appeared at 69, 115, and $137 \mathrm{ppm}$. The carbons of resorcinol aromatic ring appeared at 102, 103, 135, and 153 ppm. While carbons of vanillin aromatic ring appeared at 112, 114, 117, 139, 145, and 148 ppm. Based on FT-IR, ${ }^{1} \mathrm{H}-\mathrm{NMR}$ and ${ }^{13} \mathrm{C}-\mathrm{NMR}$ spectra can be stated that the compound of tetrakis-chloromethyl-C-4-allyloxy-3methoxyphenylcalix[4]resorcinarene has been formed.

Synthesis of calix[4]resorcinarenechitosan hybrid was conducted by reactingtetrakischloromethyl-C-4-allyloxy-3-methoxyphenylcalix [4]resorcinarene with chitosan using N,N-dimethyl formamide solvent. The use of chitosan excessive number of moles was expected that all $\mathrm{Cl}$ atoms of chloromethyl group substituted by an amine group of chitosan. Synthesis reaction of calix[4]resorcinarene-chitosan was predicted through $S_{N} 1$ mechanism. It is due to carbocation formed in this reaction will be stabilized by conjugation of electrons from the aromatic ring and solvation by the $\mathrm{N}, \mathrm{N}$-dimethylformamide solvent which is polar. Moreover, $\mathrm{NH}_{2}$ nucleophile of chitosan was steric condition. Initially, C-4-allyloxy-3-methoxyphenyl calix[4]resorcinarene releases $\mathrm{Cl}^{\prime}$ ion forming carbocation then the cation will be attacked by amine group of chitosan to form a hybrid product. Calix[4]resorcinarenechitosan hybrid was obtained as dark red solid with m.p > $300{ }^{\circ} \mathrm{C}$ (decomposed) in $78 \%$ yield. Furthermore, it was characterized by FT-IR spectrometer, XRD, and SEM. ${ }^{1} \mathrm{H}-\mathrm{NMR}$ and ${ }^{13} \mathrm{C}-\mathrm{NMR}$ spectrometer was not used for the characterization of hybrid product because of it was not soluble in solvents commonly used in ${ }^{1} \mathrm{H}-\mathrm{NMR}$ and ${ }^{13} \mathrm{C}-\mathrm{NMR}$ spectrometer.

Based on FT-IR spectrometer, it was gained $\mathrm{OH}$ group absorbance at $3426 \mathrm{~cm}^{-1}$. Absorbance of $\mathrm{C}=\mathrm{C}$ aromatic appeared at 1512 and $1605 \mathrm{~cm}^{-1}$. Absorbance of C-O-C group arised at $1142 \mathrm{~cm}^{-1}$. The data was supported by data from XRD and SEM to compare hybrid with calixarene and chitosan constituent. Based on X-ray diffraction pattern in Fig. 3, it was found information that calix[4]resorcinarenchitosan hybrid and chitosan have a semi-crystalline form. Tetrakis-chloromethyl-C-4-allyloxy-3methoxycalix [4]resorcinarene has amorphous form. From Fig. 3 also show that calix[4]resorcinarene-chitosan decreased crystallinity caused by destruction of hydrogen bonds from amine groups of chitosan. Kumirska et al., reported that destruction of hydrogen bonds in chitosan will decrease crystallinity of compounds ${ }^{21}$.

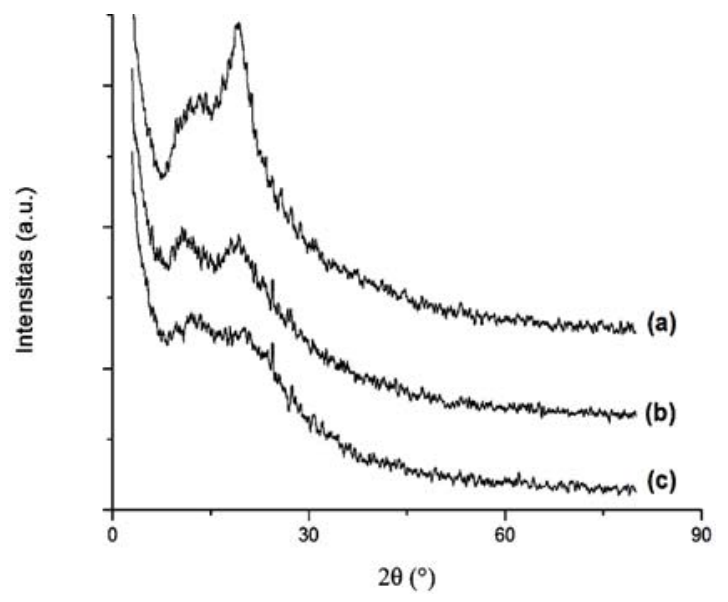

Fig. 3. X-ray diffraction pattern (a) chitosan, (b) calix[4]resorcinarene-chitosan hybrid, and (c) tetrakis-chloromethyl-C-4-allyloxy-3methoxyphenylcalix[4]resorcinarene 
SEM analysis was carried out to see the surface profile difference of calix[4]resorcinarenechitosan with chitosan and calixarene constituent. Result of SEM analysis was presented in Fig. 4. From this Fig, it can be seen that there was a difference between surface profile of calix[4] resorcinarene-chitosan with chitosan and calixarene constituent. In addition, result of SEM image analysis shows that tetrakis-chloromethyl-C-4allyloxy-3-methoxyphenylcalix[4]resorcinarene has been distributed or bound to chitosan. Based on results of FT-IR spectrometer, XRD and SEM analysis were predicted that calix[4]resorcinarenechitosan hybrid have been formed. Mechanism of hybrid formation was presented in Figure. 5.

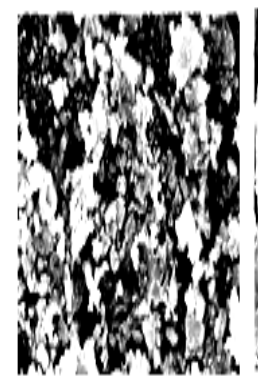

(a)

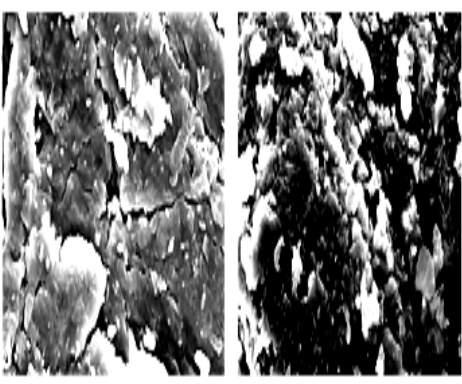

(b)

(c)
Fig. 4. SEM image of (a) tetrakis-chloromethyl-C-4allyloxy-3-methoxy phenylcalix[4]resorcinarene,

(b) chitosan, and (c) calix[4] resorcinarene chitosan hybrid

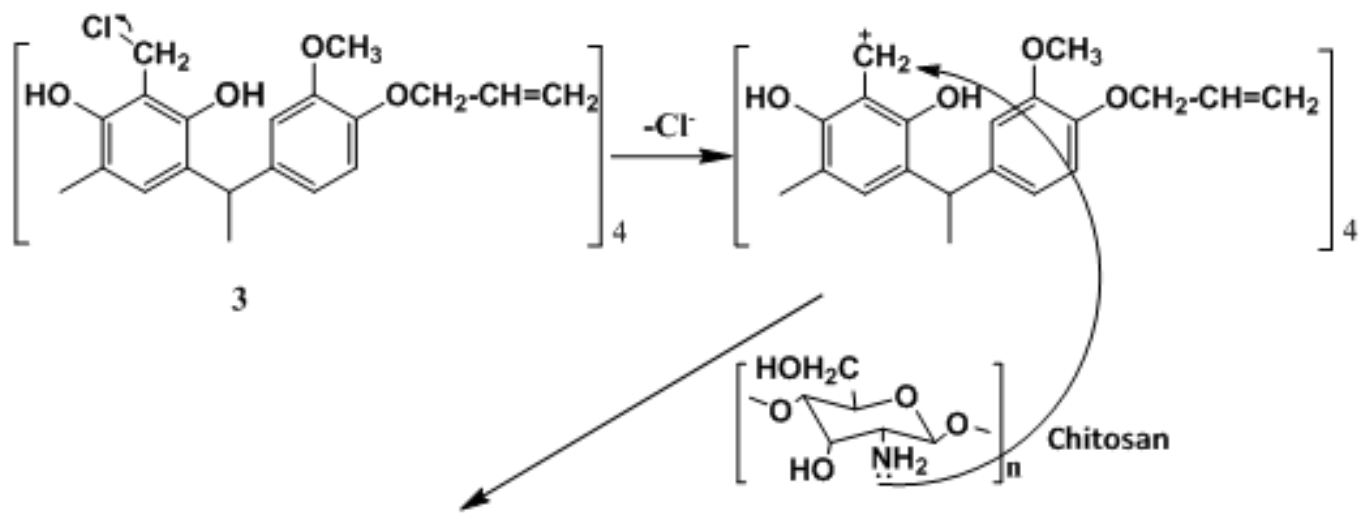

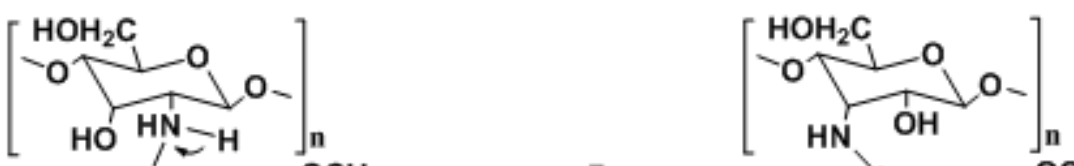<smiles>C=CCOc1ccc(C(C)c2cc(C)c(O)c(CC)c2O)cc1CC(C)C</smiles>

4

Fig. 5. Reaction mechanism of calix[4]resorcinarene-chitosan hybrid formation

\section{CONCLUSIONS}

Calix[4]resorcinarene-chitosan hybrid (4) has been synthesized through vanillin allylation, aromatic electrophilic substitution followed by cyclization, chloromethylation, and unimolecular nucleophilic substitution as well as characterized by FT-IR, ${ }^{1} \mathrm{H}-\mathrm{NMR},{ }^{13} \mathrm{C}-\mathrm{NMR}, \mathrm{XRD}$ and SEM.
Product was obtained as dark red solid with m.p. $>300{ }^{\circ} \mathrm{C}$ in $78 \%$ yield.

\section{ACKNOWLEDGEMENT}

The authors would like to thank the Directorate of Research and Community Service, Directorate General for Research and Development, Ministry of Research, Technology and Higher Education which has provided funds of this research. 


\section{REFERENCES}

1. Gutsche, C.D. In Calixarenes: Cambridge, 1989.

2. Ngurah, B.I.G.M.; Jumina; Anwar, C.; Sunardi; Mustofa, Indo. J. Chem., 2017, 17(1), 63-70.

3. Jain, V-K; Pillai, S-G; Pandya, R-A; Agrawal, Y-K; Shrivastav, P-S. Anal. Sci., 2005, 21, 129.

4. Suharso; Buhani; Suhartati, T. Indo. J. Chem., 2009, 9, 206-210.

5. Suharso; Buhani; Yuwono, S.D.; Tugiyono. Desalin. Water Treat., 2017, 68, 32-39.

6. Suharso; Buhani; Aprilia, L. Asian J. Chem., 2014, 26, 6155-6158.

7. Pietraszkiewicz, O.; Pietraszkiewicz, M. J. Inc. Phen. Mac. Chem., 1999, 35, 261-270.

8. Lu, J.; Zhang, W.; Zhang, Y.; Zhao, W.; Hu, K.; Yu, A.; Liu, P.;Wu, Y.; Zhang, S. J. Chromatogr., 2014, 13(50), 61-67.

9. Drakalska, E.; Momekova, D.; Manolova, Y.; Budurova, D.; Momekova, G.; Genova, M.; Antonov, L.; Lambov, N.; Rangelov, S. Int. J. Pharm., 2014. 4(72), 165-174.

10. Oliveira, C.B.S.; Meurer, Y.S.R.; Oliveira, MG; Medeiros, W.M.T.Q.; Silva, F.O.N.; Brito, A.C.F.; Pontes, D-L.; Neto, V.F.A. Molecules., 2014, 19, 5898-5912.

11. Jain, V-K.; Kanaiya, P-H.; Bhojak, N. Fib. Pol., 2008, 9, 720-728.
12. Nikolelis, D-P.; Petropoulou, S.S.E.; Theoris, G. Electroanalysis., 2003, 15, 1616-1624.

13. Davis, F.; Stirling, C.J.M. Langmuir., 1996, 12, 5365-5374.

14. Sal'nikov, Y-I.; Boos, G-A.; Ryzhkina, I-S.; Vagapova, L-I.; Vishnev, M-I. Russian J. Gen. Chem. 2008, 78, 1318-1323.

15. Sardjono, R.E.; Jumina; Nurwahidin, A.W.; Taufik; Sastrohamidjojo, H.; Santosa, S.J. Abstracts of Papers, International Seminar on Chemistry, Jatinangor, Oct 30-31, 2008.

16. Jumina; Sarjono R-E.; Siswanta, D.; Santosa, S-J.; Ohto, K. J. Korean Chem. Soc., 2011, 55, 454-462.

17. Utomo, S-B.; Jumina; Siwanta, D.; Mustofa. Indo. J. Chem., 2012, 12 , 49-56.

18. Timmerman, P.; Verboom, W.; Reinhoudt, DN. Tetrahedron., 1996, 52, 2663-2704.

19. Utomo, S-B.; Jumina; Siwanta, D.; Mustofa; Kumar, N. Indo. J. Chem., 2011, 11, 1-8.

20. Jumina; Siswanta, D.; Anggraeni, M.; Mardjan, M.I.D.; Mulyono, P; Ohto, K. Asian J. Chem. 2015, 27(6), 2273-2276.

21. Kumirska, J.; Czerwicka, M.; Kaczyñski, Z.; Bychowska, A.; Brzozowski, K.; Th॰ming, J; Stepnowski, P. Mar. Drugs., 2010, 8, 1567-1636. 